\title{
Studies on the Reduction of Uronic Acid Groups in Alginic Acid
}

\author{
KJELL LARSSON, ${ }^{a}$ OLLE LARM $^{b}$ and KIRSTI GRANATH ${ }^{c}$
}

\begin{abstract}
${ }^{a}$ National Laboratory for Agricultural Chemistry, P.O. Box 7004, S-750 07 Uppsala,
b Department of Chemistry and Molecular Biology, Swedish University of Agricultural Sciences, S-750 07 Uppsala and ${ }^{c}$ Pharmacia AB, P.O. Box 181, S-751 04 Uppsala, Sweden
\end{abstract}

Reduction of alginic acid by reaction with a water-soluble carbodiimide followed by treatment with sodium borohydride leads to extensive degradation of the polysaccharide. Reaction of the carboxyl functions of alginic acid with carbodiimide results in the formation of $O$-acylisourea derivatives which are sufficiently stable to be isolated. On treatment with excess sodium borohydride, the carbodiimide-activated carboxyl functions are quantitatively converted into primary alcohol functions. When insufficient carbodiimide is used for activation, the D-mannuronic acid residues in alginic acid react preferentially to the L-guluronic acid residues.

Alginate $(A)$ comprises an unbranched chain of (1-4)-linked $\beta$-D-mannuronate $(M)$ and $\alpha$-Lguluronate $(G)$ residues arranged in a blockwise fashion. ${ }^{1-5}$ There are three types of blocks: homopolymeric blocks of $M$ and $G$ residues, and blocks with alternating $M$ and $G$ residues. $A$ is present as the major structural polysaccharide of brown seaweed (Phaeophyceae) ${ }^{6}$ and the relative proportions between $M$ and $G$ residues and sequences vary between species and between tissues of the same plant. ${ }^{4}$ In previous studies we have examined the blood-anticoagulant activity of partially carboxyl-reduced and sulfated alginic acids $(A){ }^{7,8}$ It was demonstrated that the activity of the reduced and sulfated polymers increased with increasing degree of reduction. ${ }^{8}$

After activation with a water-soluble carbodiimide, uronic acid residues may be reduced with sodium borohydride to primary alcohol groups. ${ }^{9}$ In the present work, we have established conditions for reducing a given proportion of the carboxyl functions in alginates. The differ- ences in reaction rates of $M$ and $G$ residues, the mechanism for activation of the carboxyl groups with a water-soluble carbodiimide and the molecular weights of reduced alginic acids have also been studied.

\section{RESULTS AND DISCUSSION}

To study the differences between $M$ and $G$ residues during reduction, partially hydrolyzed alginic acids with different block compositions and $M / G$ ratios were prepared.

Sequences in alginic acids with alternating $M$ and $G$ residues are more soluble in aqueous acids than sequences built up to homologous blocks. ${ }^{2}$ Extensive hydrolysis leads to complete depolymerization of the regions with alternating $M$ and $G$ residues and acid-insoluble fractions consisting of more than $90 \%$ homopolymeric blocks $(H)$ can be recovered by filtration. ${ }^{3,4}$ By hydrolyzing alginic acid from different sources, the polymers $H 1, H 2$ and $H 3$ containing homologous blocks were prepared. The ratios between $M$ and $G$ residues were, as determined by ${ }^{1} \mathrm{H}$ NMR spectroscopy, ${ }^{10,11} 2.1,1.6$ and 0.6 , respectively.

During mild hydrolysis in aqueous acid, a selective depolymerization of regions with alternating $M$ and $G$ residues can be achieved. An alginic acid, rich in sequences with alternating $M$ and $G$ residues, was hydrolyzed at $\mathrm{pH} \sim 2$ for a short period and the precipitated material, containing mostly homologous blocks, was removed by filtration. After neutralization and dialysis of the filtrate, whereby oligomers were removed, a fraction consisting of at least $90 \%$ alternating $M$ and $G$ residues $(A L)$, as determined by ${ }^{1} \mathrm{H}$ NMR 
spectroscopy, ${ }^{10,11}$ was obtained in $15 \%$ yield. The fraction $A L$ had an $M / G$ ratio of 1.2.

Taylor and Conrad ${ }^{9}$ used hydroxy acids as model compounds for the reaction between polyuronides and water-soluble carbodiimides and showed that lactones were formed quantitatively. These could then be reduced to alcohols with sodium borohydride. When a carboxylic acid is reacted with a carbodiimide at constant $\mathrm{pH}$, the reaction can be followed by measuring the $\mathrm{H}^{+}$-uptake. ${ }^{9}$

At $\mathrm{pH} 4.75$, the formation of the $O$-acylisourea is favoured compared to hydrolysis and rearrangement to the $N$-acylurea derivative. ${ }^{12}$ At this pH-value, acid-base titration ${ }^{13}$ revealed that $95 \%$ of the acidic functions in alginates are ionized. When $H 1$ was allowed to react with 0.5 mol of 1-ethyl-3-(3-dimethylaminopropyl) carbodiimide (EDC) per mol uronic acid residue, 0.38 mol $\mathrm{H}^{+}$was consumed. The reaction mixture was desalted on biogel P-2, freeze-dried and analyzed by ${ }^{1} \mathbf{H}$ NMR spectroscopy. In contrast to earlier results, ${ }^{9}$ the resulting polymer was shown to contain residues with $O$-acylisourea functions. Reduction was achieved with sodium borohydride in excess at $\mathrm{pH}$ 7.0. Integration of the ${ }^{1} \mathbf{H}$ NMR spectra of $H 1$ substituted with $O$-acylisourea functions and sugar analysis of reduced $H 1$ revealed that complete reduction of the substituted glycopyranosyluronic acid residues had occurred ( $40 \%$ of the total amount of uronic acid residues). This demonstrates that reduction of EDC-activated carboxyl functions in $\mathrm{H} 1$ most probably occurs by direct substitution of the $O$-acylisourea functions and that lactones or other esters are not involved in the reaction. $\mathrm{HI}$ and $A L$ were reacted with different amounts of EDC and reduced with sodium borohydride in excess. The products were subjected to sugar anlysis (Table 1). ${ }^{14}$ When the ratio between EDC and uronic acid residues was low, preferential reduction of the $M$ residues was achieved. With increasing EDC/uronic acid residue ratios, the proportions between reduced $M$ and $G$ residues decreased. Since sodium borohydride is used in excess, the difference between the $M$ and $G$ residues in their disposition for being reduced must be due to differences in their reactions with EDC. In an attempt to study this, $H 1, H 2$ and $H 3$ were treated with different amounts of EDC, and the $\mathrm{H}^{+}$-uptake at $\mathrm{pH} 4.75$ was measured. As expected, $H 1$ (richest in $M$ residues) reacted
Table 1. $\mathrm{NaBH}_{4}$ reduction of mannuronic $(M)$ and guluronic $(G)$ acid residues in EDC-activated alginates.

\begin{tabular}{rlllr}
\hline Alginate & EDC & \multicolumn{3}{c}{ Mol \% reduction ${ }^{a}$ of } \\
& $M+G$ & $M+G$ & $M$ & \multicolumn{1}{c}{$\boldsymbol{M}$} \\
\hline \multirow{4}{*}{ H1 } & 0.25 & 19 & 26 & 5 \\
& 0.5 & 24 & 33 & 7 \\
& 2.0 & 41 & 50 & 26 \\
& 5.0 & 78 & 84 & 65 \\
& & & & \\
AL & 0.25 & 25 & 38 & 7 \\
& 0.5 & 33 & 50 & 13 \\
& 1.0 & 39 & 58 & 18 \\
& 2.0 & 45 & 63 & 24 \\
& 5.0 & 74 & 85 & 62 \\
\hline
\end{tabular}

$a$ Determined as the percentage of neutral sugar
residues. ${ }^{14}$

faster than $H 2$ and $H 3$ (richest in $G$ residues). However, $H 3$ reacted faster than $H 2$. This experiment indicates that the difference in the rate of reaction with EDC between $M$ and $G$ residues is too small to be established by measuring the $\mathrm{H}^{+}$-uptake of alginic acids with different proportions between $M$ and $G$ residues.

In an attempt to achieve complete reduction of the $M$ residues with only limited reduction of the $G$ residues, an unfractionated sample of $A$ with $M / G=1.3$ was treated with EDC portionwise and thereafter reduced and dialyzed after each portion. The neutral sugar content was determined by sugar analysis. ${ }^{14}$ A ratio between reduced $M$ and reduced $G$ of $\sim 3$ was obtained, irrespective of whether EDC was added in one, two or four portions. The recoveries were 87,75 and $66 \%$, respectively, and 49,46 and $38 \%$ of the uronic acid residues in the final products were reduced.

On reduction and dialysis of the reduced alginates, the recovery of non-dialyzable material was quantitative when equimolar amounts of EDC were used. When the reduction was performed with EDC in excess, the recovery of reduced material decreased drastically after dialysis. By comparison with alginates of known $\overline{D P}$, $H 1$ was found to have a $\overline{\mathrm{DP}}$ of $28 . \mathrm{H1}$, treated with equimolar amounts of EDC $(H 1: 1)$, with a twofold excess (H1:2), with a fivefold excess (H1:5) and $H 1$, treated with a tenfold excess of $\operatorname{EDC}(H 1: 10)$ were reduced as above. When the recovered products were gelfiltered on Sephadex 


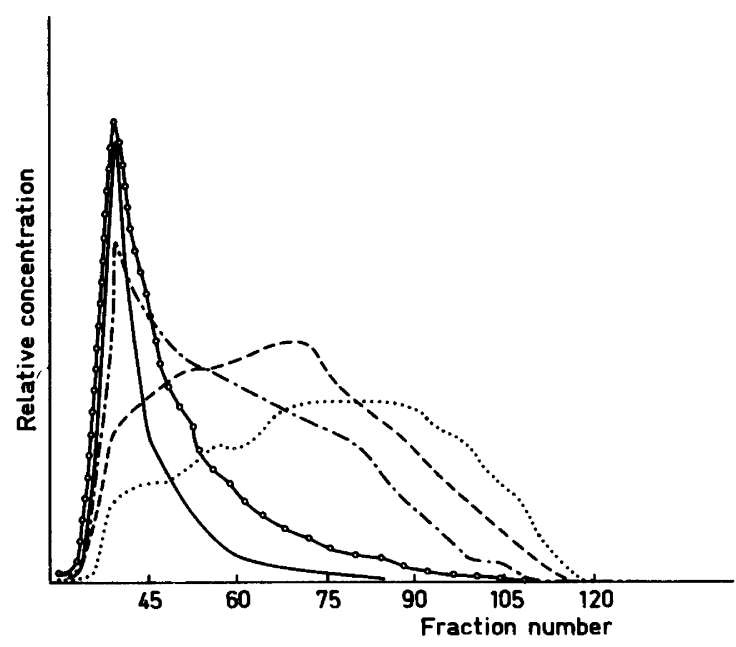

Fig. 1. Elution profiles of Sephadex G-75 of recovered $H 1$ after treatment with different molar ratios of EDC, reduction with sodium borohydride and dialysis. Starting material $(-)$, $H 1 / \mathrm{EDC}=1(-0-), H 1 / \mathrm{EDC}=0.5(-\cdot-), H 1 /$ $\mathrm{EDC}=0.2(---)$ and $H 1 / \mathrm{EDC}=0.1(\cdots)$.

G-75, the elution volumes incresed with increasing amounts of EDC added (Fig. 1). The results suggest a progressive decrease in molecular weights. In order to investigate this further, reduction was performed on an unfractionated alginic acid with a tenfold excess of EDC. The reduction was also carried out under nitrogen. The molecular weights were studied by measurements of intrinsic viscosity, low angle light scattering (LALLS) and Size Exclusion Chromatography (SEC). All these analyses verified a pronounced depolymerization of the polysaccharide chains during the reduction procedure. Reduction under nitrogen did not prevent the degradation (Table 2).

\section{Table 2.}

\begin{tabular}{lcr}
\hline Sample & $\begin{array}{l}\text { Intrinsic } \\
\text { viscosity } \\
|\eta| \mathrm{ml} \mathrm{g}\end{array}$ & \multicolumn{1}{l}{$\begin{array}{l}\text { Mol. weight } \\
\bar{M}_{\mathrm{w}}\end{array}$} \\
\hline$A$ & 372 & 184000 \\
$\begin{array}{l}\text { Reduced } A \\
\begin{array}{l}\text { Reduced } A \text { under } \\
\text { nitrogen }\end{array}\end{array}$ & 32.7 & 7300 \\
\hline
\end{tabular}

It is reasonable to assume that the depolymerization occurs by a $\beta$-elimination reaction in which 4,5-unsaturated uronic acids should be formed.

A minor absorption at $548 \mathrm{~nm}$ in the thiobarbituric acid (TBA) assay ${ }^{15}$ indicated the presence of small amounts of 4,5-unsaturated uronic acid residues in the reduced alginate. However, the amount of these residues, as calculated from the spectrum, was too small to correspond to the decrease in $\overline{\mathrm{DP}}$ of the reduced alginate. The mechanism for the degradation has to be investigated more thoroughly.

\section{EXPERIMENTAL}

General methods. Solutions were concentrated at reduced pressure below $40^{\circ} \mathrm{C}$. GLC was performed with a Packard 427 instrument, fitted with a glass capillary column $(25 \mathrm{~m} \times 0.3 \mathrm{~mm})$ coated with OV-225. Peak areas were determined with an Autolab Minigrator. ${ }^{1} \mathrm{H}$ NMR spectra were recorded with a Jeol FX-90 spectrometer in $\mathrm{D}_{2} \mathrm{O}$ at $80^{\circ} \mathrm{C}$ with sodium 3-(trimethylsilyl) propanesulfonate as internal standard. A $180^{\circ}-t-90^{\circ}$ pulse sequence $(t 2-4 \mathrm{~s})$ with a recycle time of $5 \mathrm{~s}$ was used to eliminate the solvent peak. Peak areas were determined by integration. GLC/MS was performed with a Finnigan GLC/MS Data System. Gelfiltration was performed on Sephadex G-75, G-50 and Sepharose CL-6B with $0.25 \mathrm{M}$ sodium chloride as eluent. Desalting of polymers was performed on Biogel P-2. Alginates with known DP values were kindly provided by Dr. Björn Larsen, Institutt for Marin Biokjemi, Trondheim, Norway.

Preparation of alginate fractions. To prepare acid-insoluble homopolymeric block sequences ${ }^{3}$ $(H)$ containing different proportions of D-mannuronic and $\mathrm{L}$-guluronic acid, three commercial alginates $(A)$, kindly provided by $\mathrm{Dr}$. K. Symes. Tate and Lyle, Reading, U.K., were selected. $A 1,[\alpha]_{578}-97^{\circ}\left(\mathrm{c}=0.1\right.$ in $\left.\mathrm{H}_{2} \mathrm{O}\right) ; A 2,[\alpha]_{578}-104^{\circ}$ $\left(\mathrm{c}=0.1\right.$ in $\left.\mathrm{H}_{2} \mathrm{O}\right)$; and $A 3,[\alpha]_{578}-124^{\circ}(\mathrm{c}=0.1$ in $\mathrm{H}_{2} \mathrm{O}$ ) contained 63,59 and $34 \%$ D-mannuronic acid, respectively. $A(5 \mathrm{~g})$ was dissolved in water $(230 \mathrm{ml})$ and hydrochloric acid $(\mathrm{HCl}, 3.0 \mathrm{M} ; 26$ $\mathrm{ml}$ ) was added. The mixture was hydrolyzed $\left(100^{\circ} \mathrm{C}, 5 \mathrm{~h}\right)$ and centrifuged. The precipitate was washed with $\mathrm{HCl}(0.3 \mathrm{M}, 2 \times 50 \mathrm{ml})$, suspended in water $(100 \mathrm{ml})$, dissolved by addition of aqueous sodium hydroxide $(0.5 \mathrm{M})$, dialyzed against distilled water $(4 \times 51)$ and freeze-dried. The respectively yields of the acid-insoluble homopolymeric blocks $H 1, H 2$ and $H 3$ were 2.6, 
1.8 and $2.7 \mathrm{~g}$. The preparations were characterized by ${ }^{1} \mathrm{H}$ NMR. ${ }^{10,11}$

To prepare a material consisting largely of alternating $\mathrm{D}$-mannuronic and L-guluronic acid residues, ${ }^{3,4}$ a commercial alginate $(A 4),[\alpha]_{578}$ $-105^{\circ}\left(\mathrm{c}=0.1\right.$ in $\left.\mathbf{H}_{2} \mathrm{O}\right)$ from Sigma, USA, with a high content of alternating structures was used as starting material. $A 4(5 \mathrm{~g})$ was suspended in $\mathrm{HCl}$ $(100 \mathrm{ml} ; 0.3 \mathrm{M})$ and hydrolyzed $\left(100^{\circ} \mathrm{C}, 20 \mathrm{~min}\right)$. The precipitate was removed by filtration and washed $(2 \times 10 \mathrm{ml} ; 0.3 \mathrm{M} \mathrm{HCl})$. The combined filtrates were neutralized with aqueous $\mathrm{NaOH}$ $(0.3 \mathrm{M})$, dialyzed against distilled wayer $(4 \times 5 \mathrm{l})$ and freeze-dried. The yield of non-dialyzable acid-soluble material $(A L)$ was $0.7 \mathrm{~g}$. The preparation was characterized by ${ }^{1} \mathrm{H}$ NMR. ${ }^{10,1}$

Reduction. ${ }^{9}$ In a typical experiment, the polysaccharide $(100 \mathrm{mg})$ was dissolved in water $(10$ $\mathrm{ml}$ ), $\mathrm{pH}$ was adjusted to 4.75 and solid 1-ethyl-3(3-dimethylaminopropyl) carbodiimide hydrochloride (EDC, Merck) was added. $\mathrm{pH}$ was kept constant by automatic addition of $\mathrm{HCl}(0.1 \mathrm{M})$ using a Metrohm $300 \mathrm{~B}$ pH-meter. When the reaction was complete after $2 \mathrm{~h}$, the $\mathrm{pH}$ was adjusted to 7. A large excess of aqueous sodium borohydride $(2 \mathrm{M})$ was added dropwise during 1 $\mathrm{h}$ while maintaining the $\mathrm{pH}$ at 7 by addition of $\mathrm{HCl}(4 \mathrm{M})$. The reaction mixture was allowed to stand for $1 \mathrm{~h}$, acidified with acetic acid and dialyzed for $48 \mathrm{~h}$ against distilled water $(4 \times 5 \mathrm{l})$ and freeze-dried.

When the product was to be analyzed for neutral sugars, smaller amounts $(12.5-50 \mathrm{mg})$ of polysaccharide were used and the dialysis omitted. Instead, after treatment with sodium borohydride, the reaction mixture was acidified with acetic acid and then evaporated, first to dryness and then with methanol $(5 \times 25 \mathrm{ml})$.

Sugar analysis. The partially reduced polysaccharides $(10-50 \mathrm{mg})$ were hydrolyzed in trifluoroacetic acid (TFA, $5-25 \mathrm{ml} ; 0.5 \mathrm{M} ; 100^{\circ} \mathrm{C}$; $18 \mathrm{H})$ and analyzed as their alditol acetates after reduction with sodium borohydride and acetylation. ${ }^{14,16}$ myo-Inositol (1-3 mg) was used as internal standard. L-Gulose was calculated as the sum of 1,6-anhydro-L-gulopyranose and Lgulitol.

Studies on molecular weights. Intrinsic viscosities were determined in an automatic Ubbelohde capillary viscometer (Viscomatic, Fica, France), with $0.25 \mathrm{M} \mathrm{NaCl}$ as solvent. The flow times $(t)$ were measured for five concentrations within the range of 2 to $0.5 \mathrm{mg} / \mathrm{ml}$ and for the solvent $\left(t_{\mathrm{o}}\right)$, respectively. The intrinsic viscosity $|\eta|$, is calculated graphically by plotting $\eta_{\mathrm{rel}}-1 / c$ against $c$. $\eta_{\mathrm{rel}}=t / t_{\mathrm{o}}, c=$ conc. in $\mathrm{g} / \mathrm{ml}$. A regression line through the measuring points is drawn. Intrinsic viscosity $|\eta|=\lim _{\rightarrow 0} \eta_{\mathrm{rel}-1} / c$ then is the extrapolated intersection with the $y$-axis. The results are given in Table 2. Intrinsic viscocity measures the hydrodynamic volume of the molecule and accordingly is correlated to its molecular weight in the specified system.

Absolute molecular weights (weight average) were also measured on the same samples by low angle light scattering (LALLS) technique using KMX-6 instrument (Chromatix, Cal.). The light source in this instrument is a $\mathrm{He}-\mathrm{Ne}$ laser $(\lambda=633 \mathrm{~nm})$ which in combination with a precision sample cell design allows measurements of the scattered light at small forward angles and at very low solute concentrations. Hence a simplified relation between the excess scattered light (Rayleigh Factor $R_{\theta}$ ) and the weight average molecular weight $\left(\bar{M}_{\mathrm{w}}\right)$ applies: $K c / \bar{R}_{\theta}=1 / \bar{M}_{\mathrm{w}}+2$ $A_{2} c$, where $\bar{R}_{\theta}=R_{\theta}$ solution $-R_{\theta}$ solvent, $A_{2}=$ the second virial coefficient. $K$ comprises the physical constants of the system: $K=\left(2 \pi^{2} n^{2} / \lambda^{4} N\right)$ $(\mathrm{d} n / \mathrm{d} c)^{2} \cdot\left(1+\cos ^{2} \theta\right)$, where $c=$ solute (polymer) concentration $(\mathrm{g} / \mathrm{ml}), \mathrm{d} n / \mathrm{d} c=$ refractive index increment of the polymer/solvent system $(\mathrm{ml} / \mathrm{g})$, $\lambda=$ wave length of the incident beam $(633 \mathrm{~nm})$, $n=$ refractive index of the solution, $\theta=$ scattering angle, and $N=$ Avogadro's number $\left(6.023 \times 10^{23}\right)$. Measurements were made on four concentrations within $0.5-0.1 \times 10^{-3} \mathrm{~g} / \mathrm{ml}$. The refractive index increment $0.155 \mathrm{ml} / \mathrm{g}(633 \mathrm{~nm})$ was applied, corresponding to $0.157 \mathrm{ml} / \mathrm{g}$ at white light as given by Smidsrød et al. ${ }^{17}$ The regression line through the measuring points is drawn. The intersection with $y$-axis is $1 / \bar{M}_{\mathrm{w}}$ and the slope gives the interaction parameter $A_{2}$. The results appear in Table 2.

Acknowledgements. The authors thank Professor Olof Theander for his interest and Miss Pia Annerklev for skilled technical assistance. The work was financially supported by the Swedish Board for Technical Development and the Swedish Natural Science Research Council.

\section{REFERENCES}

1. Rees, D. A. and Samuel, J. W. B., J. Chem. Soc. C. (1967) 2295.

2. Haug, A., Larsen, B. and Smidsrød, O. Acta Chem. Scand. 20 (1966) 183.

3. Haug, A., Larsen, B. and Smidsrød, O. Acta Chem. Scand. 21 (1967) 691.

4. Haug, A., Larsen, B. and Smidsrød, O. Carbohydr. Res. 32 (1974) 217.

5. Grasdalen, H., Larsen, B. and Smidsrød, O. Carbohydr. Res. 89 (1981) 179.

6. Whistler, R. L. Industrial Gums. Academic, New York 1973. 
7. Larm, O., Larsson, K., Scholander, E., Andersson, L.-O., Holmer, E., and Söderström, G. Carbohydr. Res. 73 (1979) 332.

8. Hoffman, J., Larm, O., Larsson, K., Andersson, L.-O., Holmer, E., and Söderström, G. Carbohydr. Polym. 2 (1982) 115.

9. Taylor, R. L. and Conrad, H. E. Biochemistry 11 (1972) 1383.

10. Penman, A. and Sanderson, G. R. Carbohydr. Res. 25 (1972) 273.

11. Grasdalen, H., Larsen, B. and Smidsrød, $O$. Carbohydr. Res. 68 (1979) 23.

12. Hoare, D. G. and Koshland, D. E., Jr. J. Biol. Chem. 242 (1967) 2447.

13. Haug, A. Acta Chem. Scand. 15 (1961) 950.

14. Sawardeker, J. S., Sloneker, J. H. and Jeanes, A. R. Anal. Chem. 37 (1965) 1602.

15. Weissbach, A. and Murwitz, J. J. Biol. Chem. 234 (1959) 705.

16. Jansson, D. E., Kenne, L., Liedgren, H., Lindberg, B. and Lönngren, J. J. Chem. Commun. Univ. Stockholm (1976) No. 8.

17. Smidsrød, O. and Haug, A. Acta Chem. Scand. 22 (1968) 797.

Received February 18, 1983. 